\title{
Correction to: SPG7 and Impaired Emotional Communication
}

\author{
Linwei Zhang ${ }^{1,2,4} \cdot$ Karen N. McFarland ${ }^{1} \cdot$ S. H. Subramony ${ }^{1} \cdot$ Kenneth M. Heilman $^{1}$ • \\ Tetsuo Ashizawa ${ }^{1,2,3}$
}

Published online: 27 November 2017

(C) Springer Science+Business Media, LLC, part of Springer Nature 2017

\section{Correction to: Cerebellum (2016) Vol 16(2): 595-598 \\ https://oi.org/10.1007/s12311-016-0818-5}

The original version of this article unfortunately contained an incorrect assignment of affiliations of Linwei Zhang and Tetsuo Ashizawa.

Dr. Linwei Zhang should be assigned to affiliation numbers 1,2,4 and Dr. Tetsuo Ashizawa affiliation numbers 1,2,3.

The online version of the original article can be found at https://doi.org/ 10.1007/s12311-016-0818-5

Tetsuo Ashizawa

tashizawa@houstonmethodist.org

1 McKnight Brain Institute and the Department of Neurology, College of Medicine, University of Florida, Gainesville, FL 32610, USA

2 Neuroscience Research Program, Houston Methodist Research Institute, R11-117, 6565 Fannin Street, Houston, TX 77030, USA

3 Department of Neurology, Houston Methodist Neurological Institute, R11-117, 6565 Fannin Street, Houston, TX 77030, USA

4 Department of Neurology, China-Japan Friendship Hospital, Yinghua East Street, Chaoyang District, Beijing 100029, China 